\title{
VISIBLE RANGE PHOTOCATALYSTS FOR SOLID PHASE PHOTOCATALYTIC DEGRADATION OF POLYETHYLENE AND POLYVINYL CHLORIDE
}

\author{
APEKSHA GUPTA', Y. N. LAKSHMI', R.MANIVANNAN ${ }^{1}$, S.NOYEL VICTORIA ${ }^{1,2^{*}}$ \\ ${ }^{\prime}$ Department of Chemical Engineering, National Institute of Technology, Raipur, \\ Chhattisgarh- 492010, INDIA. \\ ${ }^{2}$ Department of Chemical Engineering, National Institute of Technology Karnataka, \\ Surathkal, Karnataka-575025, INDIA.
}

\begin{abstract}
Solid phase photocatalytic degradation of polyethylene (PE) and polyvinyl chloride (PVC) with various photocatalysts such as ceria annealed at $350^{\circ} \mathrm{C}$ and $850^{\circ} \mathrm{C}$, zinc oxide annealed at $250^{\circ} \mathrm{C}$, copper sulfide and titania particles was studied under different light sources. Except titania, all the other photocatalysts performed reasonably well both in the visible and ultra-violet (UV) radiations. Ceria annealed at $850^{\circ} \mathrm{C}$ showed degradation efficiencies higher than $70 \%$ for PVC in the fluorescent and solar radiation. Ceria annealed at $350^{\circ} \mathrm{C}$ showed degradation efficiencies higher than $75 \%$ for polyethylene in fluorescent, solar and UV radiation. The Fourier transform infrared spectroscopy studies show the presence of adsorbed carbon dioxide on the degraded polymer- photocatalyst composite films. The UV-visible spectroscopic studies show that the ceria, zinc oxide and copper sulfide photocatalysts are active in the visible spectrum resulting in enhanced degradation efficiency in fluorescent and solar radiation.
\end{abstract}

Keywords: Photocatalysts; Polyvinylchloride; Polyethylene; Solar radiation.

\section{INTRODUCTION}

Continued increase in the use of plastics for various applications has led to the serious problem of white pollution [1]. Various practices have been adopted to minimize or control the white pollution caused by plastics usage. The recycling of plastics offer solution only to a lower percentage with the constraints that only smaller percentage of plastics being recycled and the process itself is time consuming and expensive [2]. Biodegradable plastics and photodegradable plastics suffer from the drawback of longer degradation time and pollution causing stabilizer is used in them [3]. Thermal and catalytic degradation of plastics demand high temperature and the need for suitable catalysts for narrow distribution of hydrocarbons [1]. Some plastics such as polyethylene are resistant to enzymatic and microbial degradation [3]. Solid phase photocatalytic degradation of plastics is popular because it is inexpensive and the degradation process occurs at moderate conditions such as room temperature and at atmospheric pressure [1]. Titanium dioxide, the commonly used photocatalyst used for various applications, is the most widely studied photocatalyst for photocatalytic plastic degradation [1-3]. Titania is active in the ultra-violet (UV) light region, with only $3-5 \%$ of UV radiation from sun reaching the earth; the efficiency of the degradation process is decreased [4-8]. To overcome this difficulty, titania photocatalysts which are active in the visible radiation have been reported in many works [4-8]. Many works report the transition metal ion implanted titania which enabled some photocatalytic reactions progress under visible light [4]. Titania treated with hydrogen peroxide or sensitized with certain dyes also has been reported to have good photocatalytic activity in visible spectrum [4]. Works on the use of other photocatalytic materials which work in the visible spectrum are very few $[4,9]$. Zinc oxide has been studied as photocatalyst for degradation of polyethylene and with and without Eosin-Y dye as sensitizer for the photocatalytic degradation of polyvinylchloride (PVC) in UV radiation [9, 10]. However studies on the use of photocatalysts which work in visible radiation other than modified titania are relatively less [11]. This work reports the use of ceria, copper sulfide and zinc oxide nanoparticles as photocatalysts for the photocatalytic degradation of polyethylene and polyvinyl chloride in visible spectrum. The nanoparticles of the photocatalysts were prepared by different liquid phase methods and characterized using X-ray diffraction (XRD), scanning electron microscopy (SEM) and UV-vis spectroscopy. The polymer-photocatalysts films were characterized for the extent of degradation using scanning electron microscopy and Fourier transform infrared (FTIR) spectroscopy.

\section{EXPERIMENTAL}

Synthesis of zinc oxide $(\mathrm{ZnO})$ nanoparticles:

Liquid phase sonochemical method was adopted for the synthesis of $\mathrm{ZnO}$ nanoparticles. Ultrasonic bath Elma $\mathrm{P} 30 \mathrm{H}$ was used for the synthesis.
Frequency of $37 \mathrm{kHz}$ was used for the synthesis of the particles. Zinc nitrate heptahydrate of $30 \mathrm{mM}$ concentration was kept in ultrasonic bath to which $60 \mathrm{mM}$ sodium hydroxide solution was added drop wise [12]. The precipitate thus formed during sonochemical reaction was collected using centrifugation followed by drying and calcination at various temperature of $100{ }^{\circ} \mathrm{C}, 150{ }^{\circ} \mathrm{C}$ and $250^{\circ} \mathrm{C}$.

Synthesis of ceria nanoparticles:

Ceria nanoparticles were prepared by the method reported by Sifontes et al. [13], chitosan $(0.8 \mathrm{~g})$ was dissolved in $40 \mathrm{~mL}$ of $3 \%(\mathrm{v} / \mathrm{v})$ acetic acid. 1 $\mathrm{M}$ of ammonium cerium nitrate was used as precursor solution. The chitosan solution and ceria precursor solution were mixed under continuous stirring and the resulting solution was added drop wise to $50 \%(\mathrm{v} / \mathrm{v})$ ammonium hydroxide solution. The resulting gel spheres were collected, dried and calcined at temperatures of $350{ }^{\circ} \mathrm{C}$ and $850{ }^{\circ} \mathrm{C}$ for $6 \mathrm{~h}$ in the muffle furnace to obtain yellow ceria particles.

Copper sulfide nanoparticles:

The copper sulfide nanoparticles were synthesized using sonochemical route explained by Singh et al., [14]. A $220 \mathrm{mM}$ copper acetate solution was used as precursor. Thiourea solution of $2 \mathrm{M}$ was prepared from $5 \% \mathrm{NaOH}$ solution. The copper precursor was placed in ultrasonic bath and the thiourea solution was added drop wise to it. The sonication was allowed to continue for an hour and the precipitate was collected and washed before drying. The sonication frequency used was $37 \mathrm{kHz}$. Copper sulfide nanoparticles were dried at $100^{\circ} \mathrm{C}$ and stored in desiccator.

Titania nanoparticles: Degussa P25 titania was used to prepare polymertitania composite in the present work. Particle size of titania particles used in this study was $25 \mathrm{~nm}$.

Preparation of polymer films:

The polyethylene (PE) (molecular weight 35,000) and polyvinylchloride (PVC) (molecular weight 62,000) crystals from Sigma Aldrich were used for preparing the composites. The solvent used for $\mathrm{PE}$ was cyclohexane based on the earlier reports [15]. Tetrahydrofuran was chosen as the solvent for PVC based on the literature [16]. To study the weight loss experiments $5 \%(\mathrm{w} / \mathrm{v})$ of the polymeric solution was prepared using the above mentioned solvents. To the polymeric solution, $1 \%(\mathrm{w} / \mathrm{v})$ of the photocatalysts were added and stirred vigorously to obtain a uniform dispersion. Apart from the synthesized nanoparticles, $\mathrm{TiO}_{2}$ nanoparticles were also used as a reference for the degradation studies. Upon complete dispersion of the photocatalysts the sample was poured manually into a petri-dish and allowed for solvent evaporation to yield a thin film of polymer with photocatalysts.

Weight loss experiments:

The initial and the final weight of the polymer composite exposed to three different radiation sources namely UV, solar radiation in open atmosphere and fluorescent light for known interval of time was noted. The loss in the weight of the polymer composite was used to calculate the degradation efficiency as given in equation 1 . 
Two, $11 \mathrm{~W}$ UV lamps from Philips were used as source for experiments under UV radiation. Two, $8 \mathrm{~W}$ fluorescent lights from Murphy were used as visible light source. For conducting the weight loss experiments in UV radiation and under fluorescent light, the samples were kept in UV proof reactor with air supply for cooling operation. For degradation studies in solar radiation, the experiments were conducted in open atmosphere during day times with maximum sunshine. The weight loss experiments in all the cases were performed for $312 \mathrm{~h}$. Pre-weighed films were kept in the different radiation environment and the weight loss was measured periodically. The degradation efficiency in other words the weight loss efficiency is calculated using the equation $1[3]$

Degradation efficiency $(\%)=($ Final weight $/$ Initial weight $) \times 100$

Characterization studies:

The morphology of the nanoparticles synthesized and the degraded polymeric films was studied by SEM (ZEISS EVO series). The crystalline nature of the annealed nanoparticles was analysed using XRD (PANalytical $3 \mathrm{~kW}$ X'pert Powder). Band gap of the nanoparticles was determined using UVvis spectroscopy (Shimadzu, UV-1800) absorbance data. The band gap of the synthesized particles was calculated using the Tauc relation (eq. 2) [14]

$$
\varepsilon h v=A\left(h v-E_{g}\right)^{n}
$$

where, $\varepsilon$ is the molar extinction coefficient, $A$ is a constant, $E_{\mathrm{g}}$ is optical band gap of the sample and $h v$ is photon energy. In this study, the value of $n$ is 2 for all the photocatalysts. The functional groups in the degraded polymeric film with and without photocatalysts were characterized using FTIR (Bruker, Alpha Model).

\section{RESULTS AND DISCUSSION}

Weight loss studies:

Table 1 shows the percentage degradation of the polymeric films with various photocatalysts annealed at various temperatures in different radiation environments after $312 \mathrm{~h}$. It is clearly seen from the Table 1 that in all types of radiation environments, the synthesized photocatalysts perform better when compared to the $\mathrm{TiO}_{2}$ nanoparticles. It is also clearly seen that the annealing temperature influences the performance of the photocatalysts. Ceria annealed at $850^{\circ} \mathrm{C}$ works better in solar and visible radiation for $5 \mathrm{wt} \%$ PVC. Ceria annealed at $350^{\circ} \mathrm{C}$ works better in the UV radiation for PVC and for PE film in all the types of radiation. $\mathrm{ZnO}$ annealed at $100^{\circ} \mathrm{C}, 150^{\circ} \mathrm{C}$ and $250^{\circ} \mathrm{C}$ works moderately for PVC film resulting in a degradation efficiency of $27 \%$ to $54 \%$ under various radiation sources. However, $\mathrm{ZnO}$ annealed at $250^{\circ} \mathrm{C}$ shows degradation efficiencies greater than $75 \%$ for $\mathrm{PE}$ in all types of radiation studied. $\mathrm{Cu} \mathrm{S}$ dried at $100^{\circ} \mathrm{C}$ showed degradation efficiency of $72 \%$ for $\mathrm{PVC}$ in solar radiation and a degradation efficiency greater than $65 \%$ for PE in all three types of radiation. The degradation efficiency for PVC is less when compared to the PE films in all the types of radiation. The PE films turned brittle and broke into small pieces, whereas the color of the PVC film turned to dark brown with exposure to all types of radiation.

Table 1. Degradation efficiency (\%) of the polymer (5 wt \%) -photocatalyst (1 wt\%) composites under various light sources after $312 \mathrm{~h}$ of exposure.

\begin{tabular}{|c|c|c|c|c|c|c|c|c|c|}
\hline \multirow[b]{3}{*}{ Treated temperature $\left({ }^{\circ} \mathrm{C}\right) \rightarrow$} & \multicolumn{8}{|c|}{ Photocatalyst } & \multirow{3}{*}{$\begin{array}{c}\text { Blank } \\
-\end{array}$} \\
\hline & \multicolumn{3}{|c|}{$\mathrm{ZnO}$} & \multicolumn{3}{|c|}{ Ceria } & \multirow{2}{*}{$\begin{array}{r}\mathbf{C u}_{\mathbf{x}} \mathbf{S} \\
100\end{array}$} & \multirow{2}{*}{$\frac{\mathrm{TiO}_{2}}{-}$} & \\
\hline & 100 & 150 & 250 & 350 & 650 & 850 & & & \\
\hline \multicolumn{10}{|l|}{ Radiation source $\downarrow$} \\
\hline & \multicolumn{9}{|c|}{ PVC - photocatalyst composite } \\
\hline Solar & 29 & 54 & 47 & 39 & 39 & 75 & 72 & 26 & 6 \\
\hline Visible & 27 & 35 & 23 & 25 & 29 & 74 & 42 & 15 & 1 \\
\hline \multirow[t]{2}{*}{ UV } & 51 & 41 & 48 & 62 & 38 & 41 & 44 & 45 & 2 \\
\hline & \multicolumn{9}{|c|}{ PE - photocatalyst composite } \\
\hline Solar & 60 & 78 & 85 & 81 & 28 & 56 & 72 & 26 & 4 \\
\hline Visible & 39 & 31 & 79 & 78 & 25 & 54 & 68 & 16 & 3 \\
\hline UV & 55 & 37 & 77 & 85 & 28 & 55 & 84 & 62 & 5 \\
\hline
\end{tabular}

FTIR studies:

Fig. 1 shows the results of the FTIR studies on PE films with and without photocatalysts after $312 \mathrm{~h}$ exposure to visible radiation. It is clearly seen that there is a doublet peak at $2360 \mathrm{~cm}^{-1}$ and $2339 \mathrm{~cm}^{-1}$ which corresponds to the adsorbed carbon dioxide $\left(\mathrm{CO}_{2}\right)[17,18]$. The peak at $668 \mathrm{~cm}^{-1}$ also corresponds to adsorbed $\mathrm{CO}_{2}[17,18]$. The intensity of the peak increases for films with photocatalysts indicating higher degradation rate of the polyethylene. There is an increased absorption in the wave numbers between $1850 \mathrm{~cm}^{-1}$ and 1650 $\mathrm{cm}^{-1}$ for polyethylene samples with photocatalysts which are characteristics of carbonyl groups [9].

The FTIR spectra of PVC ( $5 \mathrm{wt} \%$ film) - ZnO (1 wt \%) composite which was kept under visible radiation for $312 \mathrm{~h}$ is shown in Fig. 2. The peak at 693 $\mathrm{cm}^{-1}$ corresponds to C-Cl bond characteristic of PVC [19]. The peak at 3669 $\mathrm{cm}^{-1}$ represents $\mathrm{OH}$ stretching band [20]. The presence of peak at $2971 \mathrm{~cm}^{-1}$ is contribution from CH stretching [21]. The peaks at $2850 \mathrm{~cm}^{-1}, 1772 \mathrm{~cm}^{-1}$, $1426 \mathrm{~cm}^{-1}$ represent the presence of long alkyl chain, carbonyl groups and $\mathrm{CH}$ deformation respectively $[3,22,23]$. The peaks at $1332 \mathrm{~cm}^{-1}, 1198 \mathrm{~cm}^{-1}, 1097$ $\mathrm{cm}^{-1}, 1064 \mathrm{~cm}^{-1}$ represent C-O group [24-27]. The presence of carbonyl groups, $\mathrm{C}-\mathrm{O}$ bonds indicate the degradation of the PVC due to photocatalytic reaction.

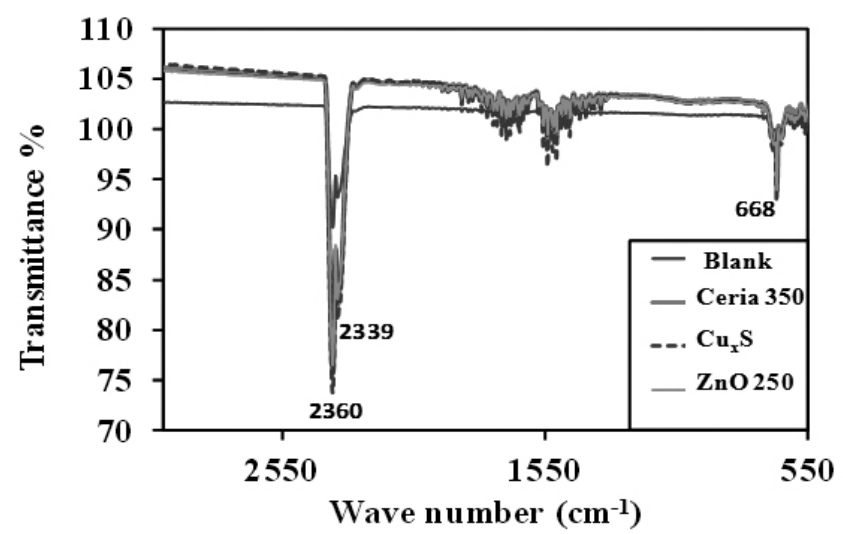

Figure 1. FTIR spectra of polyethylene (5 wt $\%$ ) with and without $1 \mathrm{wt} \%$ photocatalyst after $312 \mathrm{~h}$ of exposure to solar radiation. 


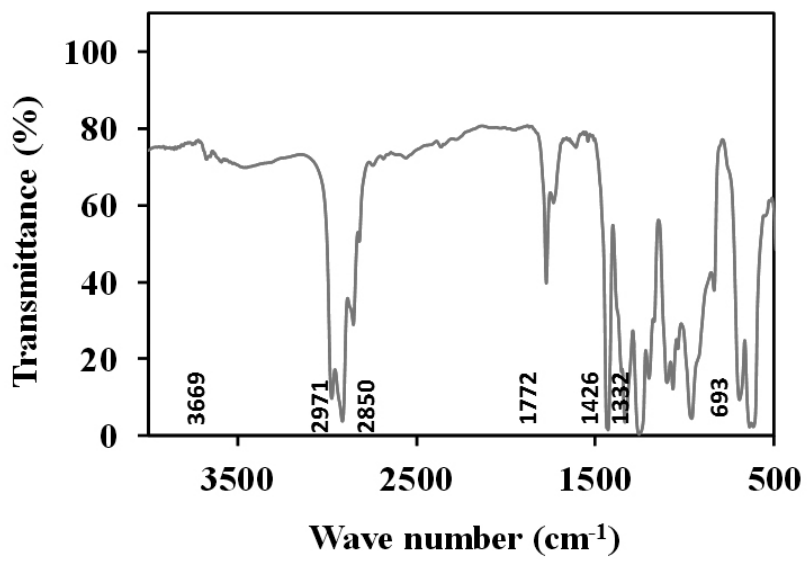

Figure 2. FTIR spectra of polyvinyl chloride ( $5 \mathrm{wt} \%$ ) with $1 \mathrm{wt} \% \mathrm{ZnO}-$ 250 after $312 \mathrm{~h}$ of exposure to solar radiation.

\section{UV- vis spectroscopy:}

The Tauc plots of $\mathrm{ZnO}$ calcined at $100{ }^{\circ} \mathrm{C}, 150{ }^{\circ} \mathrm{C}$ and $250{ }^{\circ} \mathrm{C}$, ceria particles calcined at $350^{\circ} \mathrm{C}, 650{ }^{\circ} \mathrm{C}$ and $850{ }^{\circ} \mathrm{C}, \mathrm{Cu}_{\mathrm{x}} \mathrm{S}$ particles dried at 100 ${ }^{\circ} \mathrm{C}$ and titania nanoparticles, are shown in Fig. $3-5^{\mathrm{x}}$ respectively. The band gap of the photocatalysts along with crystallite size from XRD studies is listed in Table 2. It is clearly seen from Figs. 3-5 that the annealing temperature and the synthesis route control the optical properties of the particles. The band gap of the ceria particles annealed at $300{ }^{\circ} \mathrm{C}$ is $1.8 \mathrm{eV}$ which drops slightly to 1.6 $\mathrm{eV}$ for ceria annealed at $650{ }^{\circ} \mathrm{C}$. The value again increases to $1.9 \mathrm{eV}$ for the ceria annealed at $850{ }^{\circ} \mathrm{C}$. The change in band gap value and optical properties is associated with crystal size and defects in the crystal due to annealing [28]. It was stated that the defects induced during calcinations processes increase the surface oxygen vacancies and bring the defect energy levels between the valance and conduction band of the metal oxide semiconductors which resulted in change in optical properties [28]. The band gap of the $\mathrm{ZnO}$ particles significantly decreases with annealing. The band gap of the $\mathrm{ZnO}$ particles dried at $100{ }^{\circ} \mathrm{C}$ is $3.4 \mathrm{eV}$ whereas; the heat treatment at $150{ }^{\circ} \mathrm{C}$ decreases the band gap to $1.5 \mathrm{eV}$ which again increases to $1.6 \mathrm{eV}$ on annealing at $250^{\circ} \mathrm{C}$. These changes in the band gap could be attributed to the change in morphology of the particles, crystallinity and oxygen defects in the particles [28]. The reported bandgap of the $\mathrm{ZnO}$ particles is above $3 \mathrm{eV}$ [28]. The $\mathrm{ZnO}$ particles synthesized here show a decreased band gap values which could be due to the synthesis route, morphology of the particles and oxygen defects [28, 29]. The $\mathrm{Cu}_{\mathrm{x}} \mathrm{S}$ particles dried at $100^{\circ} \mathrm{C}$ shows a band gap of $2.8 \mathrm{eV}$ and the titania nanoparticles have a band gap value of $4.6 \mathrm{eV}$. The increased photocatalytic degradation observed with the use of synthesized catalysts could be attributed to the decreased band gap of the photocatalysts.

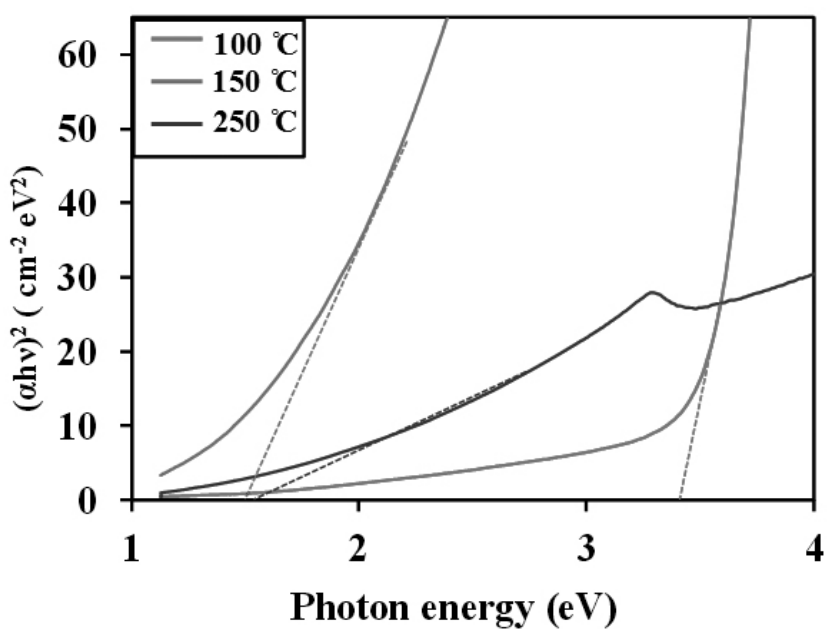

Figure 3. Tauc plots for the $\mathrm{ZnO}$ photocatalysts annealed at various temperatures.

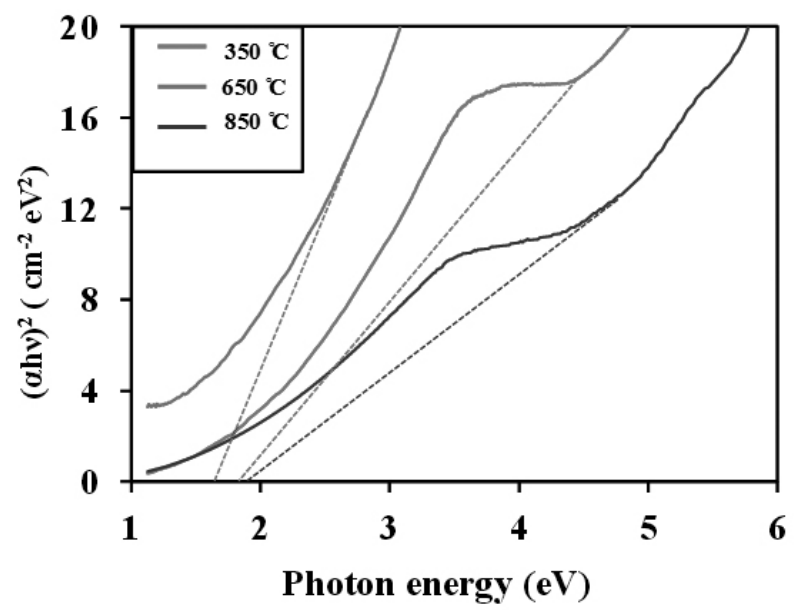

Figure 4. Tauc plots for the ceria photocatalysts annealed at various temperatures.

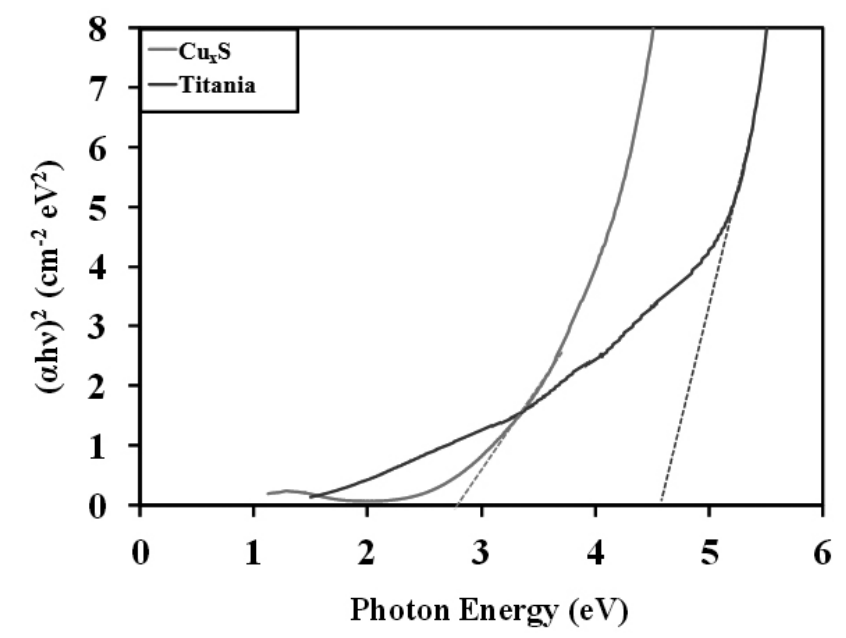

Figure 5. Tauc plot for $\mathrm{Cu}_{\mathrm{x}} \mathrm{S}$ and titania nanoparticles.

Table 2. Band gap of the photocatalysts.

\begin{tabular}{|c|c|c|}
\hline Photocatalyst & Band gap (eV) & Crystallite size \\
\hline Ceria 350 & 1.8 & 21.2 \\
\hline Ceria 650 & 1.6 & 17.3 \\
\hline Ceria 850 & 1.9 & 17.0 \\
\hline $\mathrm{ZnO} 100$ & 3.4 & 24.8 \\
\hline $\mathrm{ZnO} 150$ & 1.5 & 16.6 \\
\hline $\mathrm{ZnO} 250$ & 1.6 & 17.4 \\
\hline $\mathrm{Cu} \mathrm{x}_{\mathrm{s}}$ & 2.8 & 38.6 \\
\hline Titania & 4.6 & 14.2 \\
\hline
\end{tabular}

$X$-ray Diffraction analysis:

Figs. 6 - 9 show the XRD patterns for ceria, $\mathrm{ZnO}, \mathrm{Cu}_{\mathrm{x}} \mathrm{S}$ and titania particles heat treated at different temperatures respectively. The results show that the ceria particles have face centered cubic (FCC) fluorite structure, which matches well with the reported literature [30]. The intensity of the peaks increase with increased annealing temperature indicating increase in crystallinity. The Scherrer's formula was used to calculate the crystallite size of the annealed particles. Scherrer's formula is given by equation 3 . 


$$
D=\frac{0.9 \lambda}{\beta \cos \theta}
$$

where, $D$ is the average crystallite size, $\lambda$ is the $\mathrm{X}$-ray wavelength which is equal to $1.54 \AA, \theta$ is the Bragg's diffraction angle and $\beta$ is the full width at half maximum (FWHM) [31]. The crystallite size of the annealed samples is tabulated in Table 2 . The crystallite size of ceria particles decreases slightly with increase in annealing temperature. The XRD pattern of the $\mathrm{ZnO}$ samples shows the presence of pure hexagonal phase $\mathrm{ZnO}$ [31]. The crystallite size of $\mathrm{ZnO}$ particles decreases with increase in heat treatment temperature.

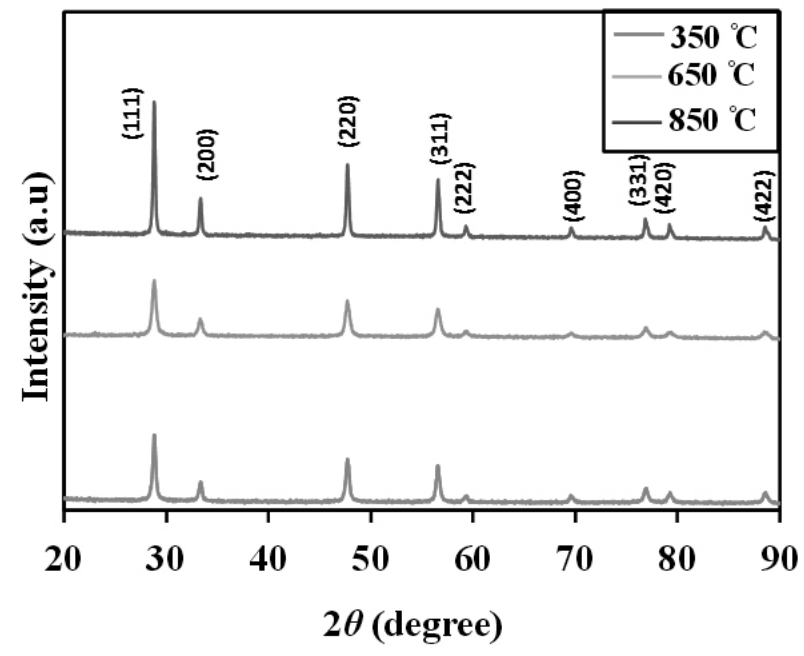

Figure 6. XRD pattern for the ceria photocatalysts treated at different temperatures.

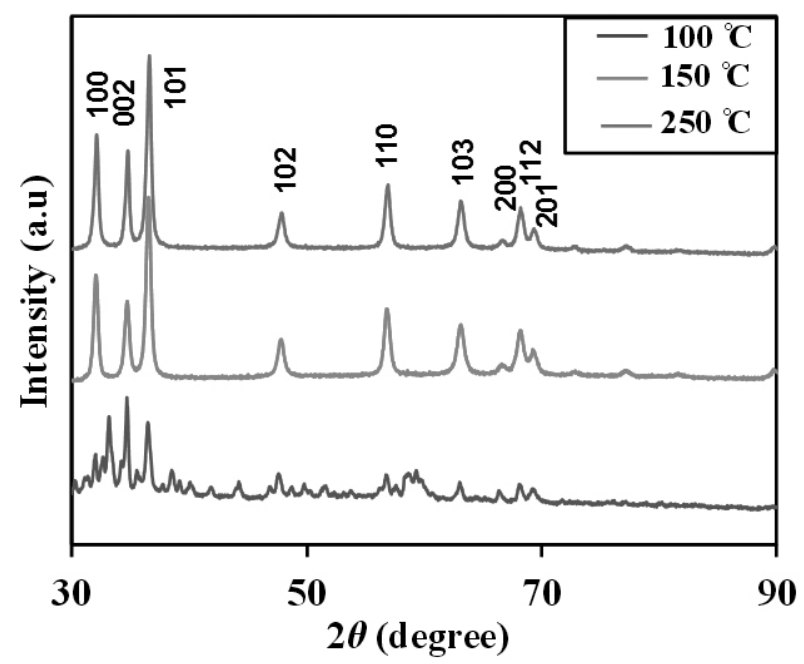

Figure 7. $\mathrm{XRD}$ pattern for the $\mathrm{ZnO}$ photocatalysts treated at different temperatures.

Scanning Electron Microscopy (SEM):

Fig. 10 (a-d) shows the SEM images of the synthesized photocatalyst particles treated at different temperatures. Table 3 shows the results of EDAX analysis of the photocatalyst synthesized and heat treated at various temperatures. From Fig. 10a, it is clearly seen that the $\mathrm{ZnO}$ particles dried at $100^{\circ} \mathrm{C}$ resemble thin flakes/ sheets. The morphology of the $\mathrm{ZnO}$ particles changes to spherical particles after heat treatment at $150^{\circ} \mathrm{C}$. This is clearly seen in Fig. 10b. The shape of the $\mathrm{ZnO}$ particles further changes to small disc form with increased degree of agglomeration upon heating at $250^{\circ} \mathrm{C}$, as observed in Fig. 10c. Similarly the ceria particles show increased agglomeration, as seen in Fig. 10d. EDAX analysis of the photocatalyst is tabulated in Table 3. Table 3 shows that the oxygen concentration in $\mathrm{ZnO}$ samples decreases with increase in annealing temperature. This shows that the oxygen vacancies are increasing with annealing temperature. In ceria particles the oxygen concentration decreases when the annealing temperature increases from $350^{\circ} \mathrm{C}$ to $650^{\circ} \mathrm{C}$ and increases again at $850^{\circ} \mathrm{C}$. The oxygen vacancies are known to control the photocatalytic properties of the semiconductor particles [32, 33].

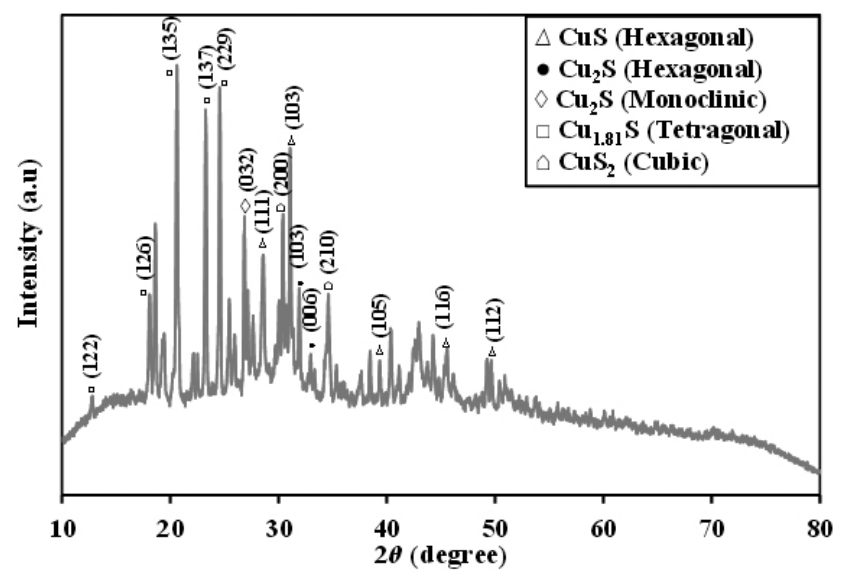

Figure 8. XRD pattern for the $\mathrm{Cu}_{\mathrm{x}} \mathrm{S}$ photocatalyst.

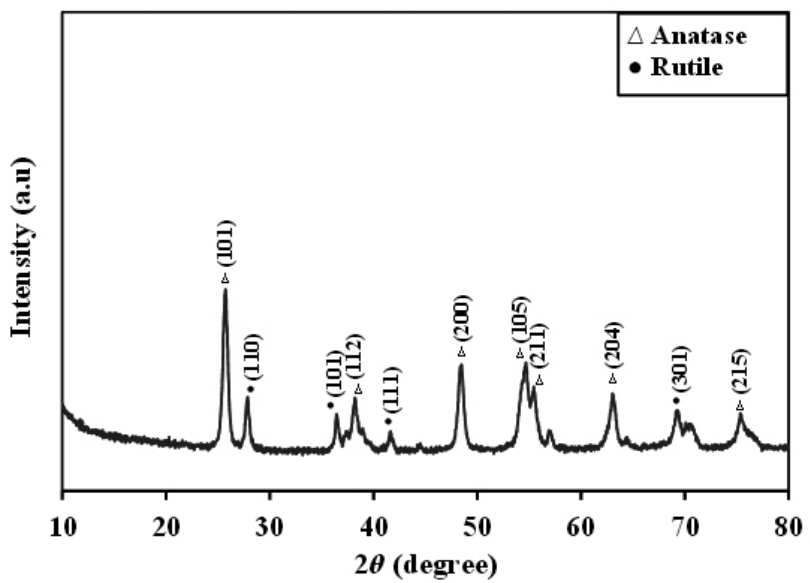

Figure 9. XRD pattern for the titania photocatalyst.

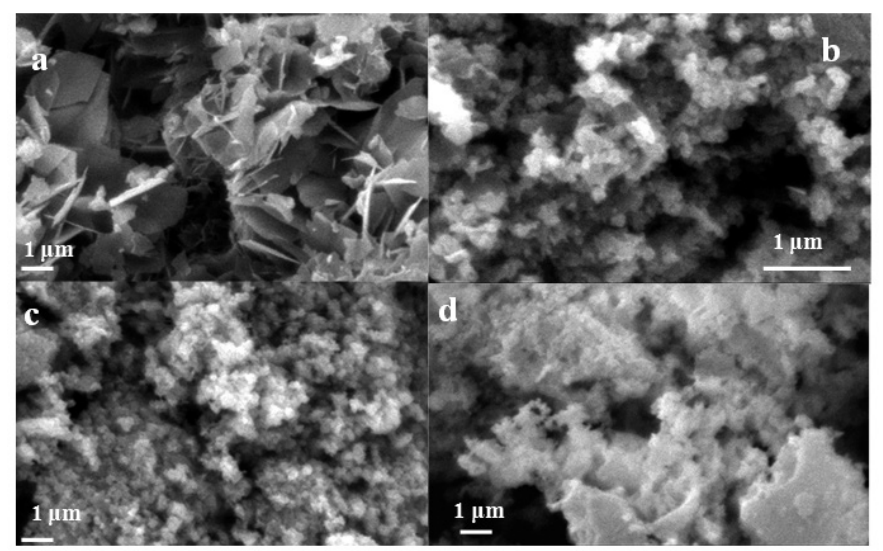

Figure 10. SEM images of particles treated at different temperatures a) $\mathrm{ZnO}$ at $100^{\circ} \mathrm{C}$ b) $\mathrm{ZnO}$ at $150^{\circ} \mathrm{C} \mathrm{c}$ ) $\mathrm{ZnO}$ at $250^{\circ} \mathrm{C}$ d) ceria at $350^{\circ} \mathrm{C}$.

Figs. 11 and 12 show the SEM images of the PE and PVC films respectively, with $1 \mathrm{wt} \%$ zinc oxide photocatalyst after exposure to visible radiation for different durations. It is clearly seen that the PE and PVC films 
with zero irradiation time to solar radiation, presents smoother surface which indicates the absence of degradation process. The polymer-photocatalyst composite shows the presence of small cavities when exposed to visible radiation. The cavities increase in size and number with increase in exposure time. The appearance of such cavities shows the extent of damage caused to the film due to photocatalytic degradation. The formation of cavities on the film surface could be attributed to the formation of volatile products which escape during the degradation process and cause damage to the polymeric structure [2]. The damage caused to the films increases with increase in the exposure time to solar radiation.

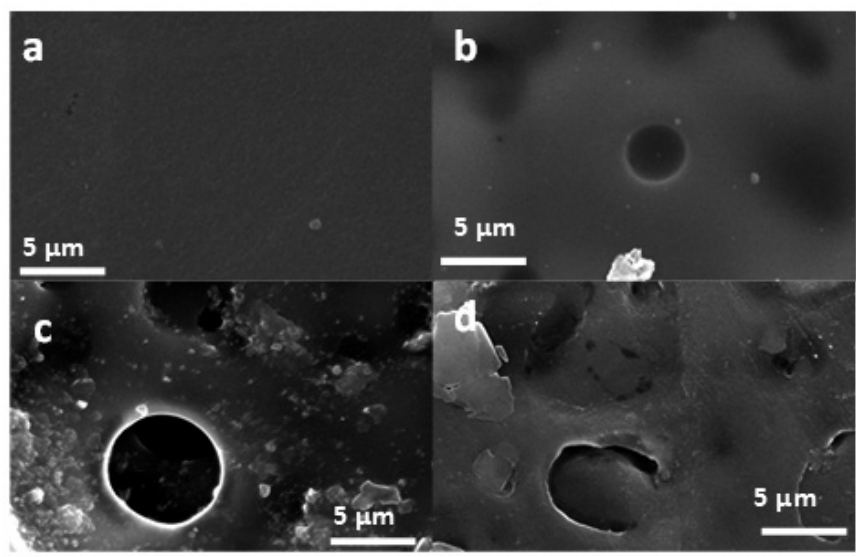

Figure 11. SEM images of polyethylene (5 wt $\%)$ - $\mathrm{ZnO}(1 \mathrm{wt} \%)$ composite in solar radiation at different exposure times a) $0 \mathrm{~h} \mathrm{~b}) 96 \mathrm{~h} \mathrm{c)} 216 \mathrm{~h} \mathrm{d)} 312 \mathrm{~h}$.

Table 3: EDX composition of the synthesized photocatalyst followed by annealing at various temperatures.

\begin{tabular}{|c|c|c|c|}
\hline & Ceria $350{ }^{\circ} \mathrm{C}$ & Ceria $650{ }^{\circ} \mathrm{C}$ & Ceria $850{ }^{\circ} \mathrm{C}$ \\
\hline $\mathrm{Ce}$ & 85.1 & 90.7 & 84.2 \\
\hline \multirow[t]{2}{*}{$\mathrm{O}$} & 14.9 & 9.3 & 15.8 \\
\hline & $\mathrm{ZnO} 100^{\circ} \mathrm{C}$ & $\mathrm{ZnO} 150^{\circ} \mathrm{C}$ & $\mathrm{ZnO} 250^{\circ} \mathrm{C}$ \\
\hline $\mathrm{Zn}$ & 72.1 & 85.4 & 87.3 \\
\hline $\mathrm{O}$ & 27.9 & 14.6 & 12.7 \\
\hline
\end{tabular}

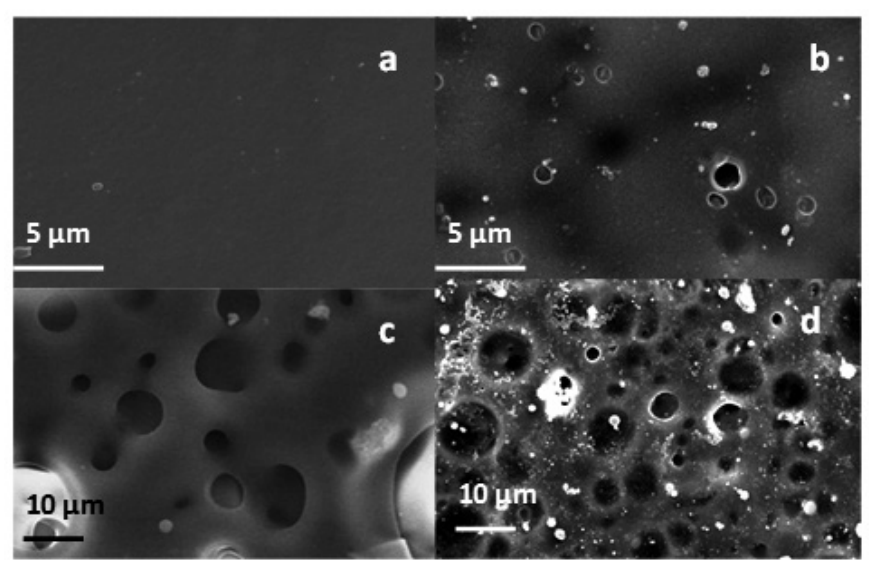

Figure 12. SEM images of polyvinyl chloride (5 wt $\%)-\mathrm{ZnO}(1 \mathrm{wt} \%)$ composite in solar radiation at different exposure times a) $0 \mathrm{~h} \mathrm{~b}$ ) $96 \mathrm{~h}$ c) 216 h d) $312 \mathrm{~h}$.

\section{Mechanism}

The annealing temperature of the particles was found to have significant effect on the photocatalytic activity of the particles. The synthesis route was also found to control the oxygen vacancies of the particles $[28,29]$. The oxygen vacancies in the $\mathrm{ZnO}$ particles heat treated at $250^{\circ} \mathrm{C}$ is more when compared to the $\mathrm{ZnO}$ particles treated at 100 and $150^{\circ} \mathrm{C}$. Similarly the oxygen vacancies are high for ceria calcined at $650^{\circ} \mathrm{C}$. The photocatalytic activity of any semiconductor material is not always directly proportional to its activity. There exists an optimum oxygen vacancy. Too high an oxygen vacancy will lead to recombination resulting in free charge mobility [32]. A high surface area promotes the photocatalytic activity even in the case of low oxygen vacancy [34]. $\mathrm{ZnO}$ particles calcined at $250^{\circ} \mathrm{C}$ shows the presence of smaller sized particles with increased oxygen vacancy that works better under all types of radiation for $5 \mathrm{wt} \% \mathrm{PE}$ film. Similarly ceria particles treated at $350^{\circ} \mathrm{C}$ shows lower agglomeration which performs well for $\mathrm{PE}$ film under all radiation types. In the case of CuxS photocatalysts, $\mathrm{Cu}^{2+}$ can be reduced to $\mathrm{Cu}^{+}$which is a strong oxidizer [35].

The photocatalytic degradation of $\mathrm{PE}$ - photocatalyst composite has been studied widely under different radiations and the mechanism have been proposed $[2,3,9,11,15]$. The photocatalyst particles absorb the radiation depending on their band gap and form holes and electrons in valence and conduction band respectively [3] as shown in reaction (i). These further react with oxygen resulting in the formation of active oxygen species namely $\mathrm{OH}, \mathrm{O}_{2}{ }^{--}$shown by reactions (ii-v). These active oxygen species further degrade the polymer chain. The diffusion of the active oxygen species causes the degradation of the entire polymer matrix. This degradation causes the formation of carbonyl and carboxyl groups generation which upon further reaction produce $\mathrm{CO}_{2}$ and $\mathrm{H}_{2} \mathrm{O}$ $[2,3,9,11,15]$. The liberation or generation of $\mathrm{CO}_{2}$ with the degradation of $\mathrm{PE}^{2}$ is also proved by the FTIR peaks at $2360 \mathrm{~cm}^{-1}$.

$$
\text { Photocatalyst }+h v \rightarrow \mathrm{e}+\mathrm{h}
$$

$\mathrm{O}_{2(\text { ads })}+e^{-} \rightarrow \mathrm{O}_{2}^{-}$

$\mathrm{O}_{2}^{-}+-\left(\mathrm{CH}_{2} \mathrm{CH}_{2}\right)-^{+} \rightarrow-\left(\mathrm{C} . \mathrm{HCH}_{2}\right)-+\mathrm{HO}_{2}{ }^{-}$

$2 \mathrm{HO}_{2}{ }^{\cdot} \rightarrow \mathrm{H}_{2} \mathrm{O}_{2}+\mathrm{O}_{2}$

$\mathrm{H}_{2} \mathrm{O}_{2}+h v \rightarrow 2 \mathrm{OH}^{*}$

Similar kind of photocatalytic reactions are also believed to occur in PVCphotocatalyst composites. Two free radicals take part in the photocatalytic degradation of PVC; chloroalkyl radical which releases $\mathrm{HCl}$ on degradation and chloro-peroxy radical which is believed to be produce hydroxyl and carbonyl groups [36]. PVC which is degraded to a little extent with discoloration is claimed to be photostable due to the presence of large bonds which serve as oxygen and free radical scavengers [36]. This could be a reason for lower degradation rate of PVC when compared to PE films. The photocatalysts absorb light which result in the generation of electron-hole pair in the conduction and valence band respectively. The reaction of the generated species with adsorbed oxygen creates active oxygen species shown by reactions $(i-v)$. Further degradation disturbs the chain resulting in carbon centered radicals which upon further reaction releases carbon dioxide [37].

\section{CONCLUSION}

An attempt to degrade the polyethylene and poly vinyl chloride using ceria, copper sulfide and zinc oxide particles as photocatalysts in the place of conventionally used titania nanoparticles was made. The synthesized photocatalysts were found to work satisfactorily even under visible radiation and solar radiation. The synthesized photocatalysts performed better than the titania particles under solar radiation, illumination using fluorescent lamp and under UV radiation. The increase in the peak intensities corresponding to adsorbed $\mathrm{CO}_{2}$ indicate higher degradation rate of the PE-photocatalyst with increase in duration of exposure to light source. The presence of carbonyl bonds suggests the degradation of PVC-photocatalyst composite. Ceria calcined at $850^{\circ} \mathrm{C}$ worked better than other photocatalysts for PVC under solar and fluorescent light source. Ceria calcined at $350^{\circ} \mathrm{C}$ performed better under UV radiation for PVC. Titania exhibited lower degradation efficiency for both the polymers under all radiation types. 


\section{REFERENCES}

1. J. Shang, M.Chai, Y. Zhu, J. Solid State Chemistry. 174, 104, (2003).

2. W. Asghar, I.A. Qazi, H. Ilyas, A.A. Khan, M.A. Awan, M.R. Aslam, J. Nanomaterials, 1, (2011).

3. X.U. Zhao, Z. Li, Y. Chen, L. Shi, Y. Zhu, J. Molecular Catalysis A: Chemical 268, 101, (2007).

4. Fa W, Zan L, Gong C, Zhong J, Deng K, Applied Catalysis B: Environmental 79, 216, (2008).

5. C. Yang, C. Gong, T. Peng, K. Deng, L. Zan, J. Hazardous Materials 178, $152,(2010)$.

6. X. Zhao, Z. Li, Y. Chen, L. Shi, Y. Zhu, Applied Surface Science 254, $1825,(2008)$.

7. F. Zhang, S.W. Chan, J.E. Spanier, E. Apak, Q. Jin, R.D. Robinson, I.P. Herman, Applied Physics Letters 80, 127, (2002).

8. M.K. Mohammad, H. Amin, N. Nasim, M. Lee, Materials Research 17,1039, (2014).

9. R. Yang, P.A. Christensen, T.A. Egerton, J.R White, J Polymer Degradation and Stability 95, 1533, (2010).

10. S. Chakrabarti, B. Chaudhuri, S. Bhattacharjee, P. Das, B.K. Dutta, J Hazardous Materials 154, 230, (2008).

11. M. Pelaez, N.T. Nolan, S.C. Pillai, M.K. Seery, P. Falaras, A.G. Kontos, S.M.D. Patrick, D.D. Dionysiou, Applied Catalysis B: Environmental 125, 331, (2012).

12. T. Wirunmongkol, N. Charoen, S. Pavasupree, Energy Procedia 34, 801, (2013).

13. A.B. Sifontes, M. Rosales, F.J. Mendez, O. Oviedo, T. Zoltan, J. Nanomaterials, 1, (2013).

14. A. Singh, R. Manivannan, S.N. Victoria, Arabian Journal of Chemistry, Article in press, (2015).

15. R.T. Thomas, N. Sandhyarani, RSC Advances 3, 14080, (2013).

16. M. Zhang, J. Wu, D. Lu, J. Yang, International J. Photoenergy, 2013, (2013).

17. R. Bini, V. Schettino, Imperial College Press, London, 259, (2014).

18. R.K.Velu Microbiological Research in Agroecosystem Management, Springer India, 2013.
19. Y.V. Glazkovskii, V.E. Zgayevskii, S.P. Ruhinskii, N. M. Bakardzhiyev, Vysokomol. Soyed 8, 1472, (1966).

20. E. Balan, A.M. Saitta, F. Mauri, G. Calas, American Mineralogist 86, 1321, (2001).

21. T.S. Renuga Devi, S. Gayathri, International J. Pharmaceutical Sciences Review and Research 2, 106, (2010).

22. E.Yousif, J Taibah Uni. for Sci. 7, 79, (2013).

23. X. Colom, F. Carrillo, F. Nogues, P. Garriga, Polymer Degradation and Stability 80, 543, (2003).

24. D. Jain, H.K. Daima, S. Kachhwaha, S.L. Kothari, Digest J. Nanomaterials and Biostructures 4, 557(2009).

25. M. Arivazhagan, K. Sambathkumar, S. Jeyavijayan, J. Pure and Applied Physics 48, 716-722, (2010).

26. S.G. Prasad, A. De, U. De, International J. of Spectroscopy 810936, 1, (2011).

27. G.S. Uthayakumar, J. Chandhuru, S. Inbasekaran, A. Sivasubramanian, Asian J. Biomedical and Pharmaceutical Sci. 3, 12, (2013).

28. S. Bhattacharyya, A. Gedanken, Microporous and Mesoporous Materials 110, 553, (2008).

29. R.Vajtai, Springer Handbook of Nanomaterials 528, 2013.

30. A.M.D. Farias, D.N. Thanh, M.A. Fraga, Applied Catalysis B: Environmental 93, 250, (2010).

31. Y.T. Prabhu, K.V. Rao, V.S.S. Kumar, B.S. Kumari, Advances in Nanoparticles 2, 45, (2013).

32. H. Tan, Z. Zhao, W. Zhu, E.N. Coker, B. Li, M. Zheng, W. Yu, H. Fan, Z. Sun, Appl. Mater. Interfaces 6, 19184, (2014).

33. S.K. Anirban, T. Paul, A. Dutta, RSC Adv. 5, 50186, (2015).

34. J. W. Hu, Advanced Materials and Structural Engineering, CRC Press London, (2016).

35. H.R. Pouretedal, A. Norozi, H. Keshavarz, A. Semnani, J. Hazardous Materials 162, 674, (2009).

36. D.B. Smith, Photochemistry, Royal Society of Chemistry 17, (1986).

37. S. Cho, W. Choi, J. Photochemistry and Photobiology A: Chemistry 143, 221, (2001). 